\title{
LVII. On a modified resistance-balance
}

\section{Professor Silvanus P. Thompson B.A. D.Sc.}

To cite this article: Professor Silvanus P. Thompson B.A. D.Sc. (1884) LVII. On a modified resistance-balance, Philosophical Magazine Series 5, 17:109, 507-509, DOI: 10.1080/14786448408627550

To link to this article: http://dx.doi.org/10.1080/14786448408627550

$$
\text { 曲 Published online: } 29 \text { Apr } 2009 .
$$

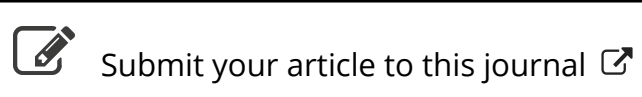

Џلl Article views: 2

Q View related articles $\sqsubset$ 
LVII. On a Modified Resistance-Balance. By Professor Siluanus P. Thompson, B.A., D.Se.*

[Plate XVI.]

QEVERAL forms of Resistance-Balance modified for the 5 purpose of facilitating the accurate measurement of small resistances or small differences of resistance are known. The modification due to Prof. Fleeming Jenkint, and the Doublebridge of Sir W. Thomson $\ddagger$ are perhaps the earliest and least-known of these. Kirchhoff's arrangement, as further modified by Matthiessen, is well known under the name of the "divided-metre" bridge. The method of using this form of balance suggested by Professor G. Carey Foster $\S$, in which the difference between two nearly equal resistances is expressed directly in terms of a length of a graduated wire whose resistance is very accurately known, is so extremely reliable, that probably no one who once adopts this method of testing resistances will ever go back to the cruder and less accurate methods. The essence of the method lies in arranging the coil whose resistance is to be measured and the standard coil to which it approximates in series with the graduated wire, in such a manner that the positions of the two coils can be interchanged. The points of the wire at which the potential is the mean between the potentials at the two ends of the series having been determined, both before and after the interchange, the resistance of the length between these two points is the desired difference. A special modification of the balance for facilitating Foster's method was described to the Physical Society in Dec. 1879 by Dr. J. A. Fleming \|; and has been since then systematically used in the Cavendish Laboratory by the Committee on Electrical Standards for the comparison of standard coils. Although extremely convenient, Dr. Fleming's Balance appears to me to be open to several objections. In the first place, the interchange of the two coils, though much more easily accomplished than in the older divided-metre form, is effected by lifting the terminals of each coil out of one of two pairs of mercury-cups, and removing them to the other pair. This operation is not

* Communicated by the Physical Society. Read February 23, 1884.

$\uparrow$ Report of Committee on Electrical Standards.

+ Proc. Roy. Soc. vol. xi. p. 313 (1861).

$\$$ Proc. Soc. Telegr. Engin. vol. i. pt. 2, p. 196 (1872).

II Proc. Phys. Soc. vol. iii. p. 174; Phil. Mag. ser. 4, vol. ix. p. 100 (1880) ; Telegr. Journal, vol. viii. p. 3 (1880). 
convenient in certain cases, as, for example, when the resistance is being taken of a wire heated in an oil-bath to various successive temperatures, or when some contact-resistance is to be measured which must on no account be shaken. Again, in Fleming's Balance the graduated wire is bent into a circle and laid in a groove, contact being made by a trigger attached to an arm, pivoted at the centre of the circular wire. This arrangement, though $I$ have heard no complaint of its practical efficiency, is open to two objections. It must be much more difficult to lay the wire with an even stress at all points than is the case with a straight wire stretched between two points. The range of resistances measurable by this bridge is limited to something less than the actual resistance of the graduated wire. Lastly, a circular scale having about $300^{\circ}$ divided into 1000 parts is not so easily obtained as a straight metre-scale.

I have therefore designed a form of resistance-balance which meets the desiderata. It consists of two parts-a divided wire or rheocord, and an arrangement of mercurycups, connecting-pieces, and terminals to be attached at the back of the rheocord part. The figure 1, Plate XVI., shows the general arrangement of these two parts ; the connexions between the two parts being made by strips of copper 3 millim. thick, secured under clamping-screws. $X$ is the coil whose resistance is to be measured, and $\mathrm{S}$ the standard coil. The terminals of each of these coils dip into two large mercurycups turned in solid copper; these are shown half size in fig. 2 , and are marked $m n$ and $m^{\prime} n^{\prime}$ respectively. Between these cups lie four parallel bars of solid copper $a a^{\prime}, b b^{\prime}, c c^{\prime}$, and $d d^{\prime}$, the ends of which terminate also in mercury-cups. The bars $a a^{\prime}$ and $b b^{\prime}$ communicate by stout copper connexions with the two ends of the rheocord part. The other two bars communicate with the battery terminals and with the terminals for the two balanced coils $A$ and $B$. In all accurate tests these coils should be approximately equal to the $\mathrm{X}$ or $\mathrm{S}$, and should be very nearly equal to one another. As they are not required to be interchanged, they are simply clamped with copper connexions under flat-headed terminal screws. Short stout pieces of copper, amalgamated at the ends, serve to connect the mercury-cups as shown in fig. $1, m$ being connected with $a, n$ with $d, m^{\prime}$ with $b^{\prime}$, and $n^{\prime}$ with $c^{\prime}$. The connexions being thus made, an observation is taken, and the distance $x$ along the scale of the point of contact with the galvanometer-circuit is recorded. Then the connexions are altered, $m$ being placed in communication with $b$, $n$ with $c, m^{\prime}$ with $a^{\prime}$, and $n^{\prime}$ with $d^{\prime}$. This has the 


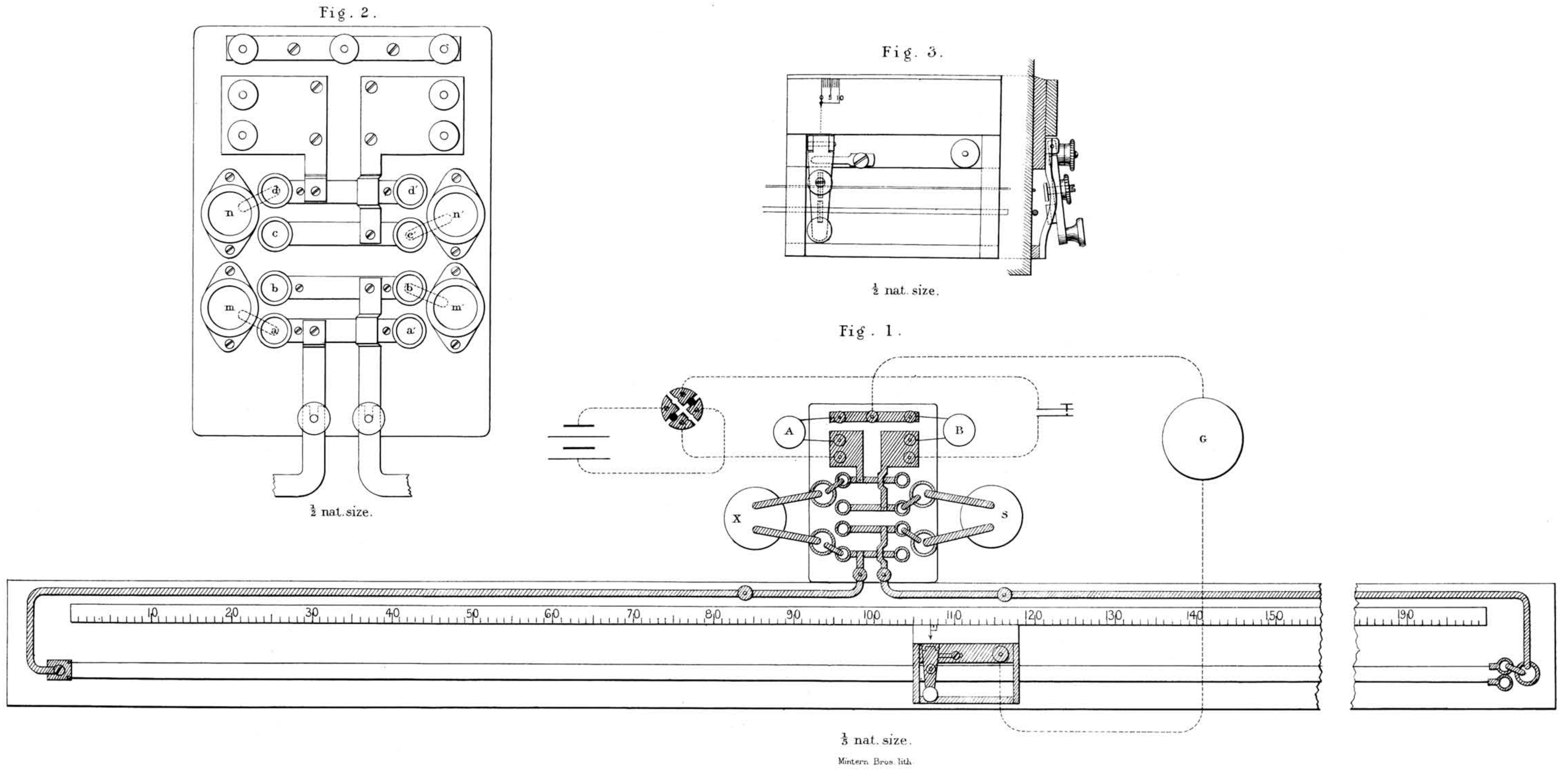


same effect as if $X$ and $S$ were bodily interchanged; and without lifting either of those coils as in Fleming's instrument. Balance having been once more obtained, and a new reading $x^{\prime}$ of the scale having been taken, the length $x-x^{\prime}$, multiplied by the resistance per centim. of the divided wire, is equal to the actual difference between $\mathrm{X}$ and $\mathrm{S}$.

The switch-board part is made of such dimensions that it can be attached on to any of the ordinary pattern of metrebridges. The ordinary metre-balance is, however, limited in its application, so far as Foster's method of comparison is concerned, to the comparison of resistances which do not differ by a greater amount from one another than the actual resistance of the wire of the rheocord part. To facilitate the comparison of coils of high resistance whose resistances differ by several ohms, I have adopted the following arrangement of the rheocord part. Two wires are selected, each two metres long, one having a resistance of about a quarter of an ohm, the other from eight to ten ohms. They are stretched parallel upon a board 213 centim. in length, provided with a two-metre scale, which should be divided into millimetres. Either of these wires can be used at will, connexion being made to either at one end of the bridge by a stout copper link dipping into mercury-cups drilled in the wood and lined with copper. Stout copper rods of about 1 square centim. section lead from the ends of the stretched wires to the screws, by which the switch-board part is connected with the rheocord part. The galvanometer-contact is made by means of a sliding key shown separately in fig. 3, which is provided with a vernier, and which by a simple arrangement can be set so as to make the contact with either the thick or the thin wire, as may be desired. In the instrument exhibited to the Society the stout wire is of germansilver 2.1 millim. in diameter, and of $0.2385 \mathrm{ohms}$ resistance. The thin wire is of silver-platinum alloy; its diameter is 0.33 millim., and its resistance $8.21 \mathrm{ohms}$. The form of slider adopted is a much more well-conditioned arrangement than the usual heavy medal sliding key standing on three legs, and is more convenient in practice. The greater length of rheocord, though it renders the instrument less portable, increases the range of the instrument without affecting its sensitiveness.

Phil. Mag. S. 5. No. 109. Suppl. Vol. 17. 